\title{
Hypertension, obesity and central obesity in diabetics and non diabetics in Southern Ethiopia
}

\author{
Araya Giday ${ }^{1}$, Mistire Wolde ${ }^{2}$, Dawit Yihdego ${ }^{1}$
}

\section{Introduction}

The number of adults with diabetes in the world will rise from 135 million in 1995 to 300 million by the year 2025 . The major part of this numerical increase will occur in developing countries, including Africa $(1,2)$. Diabetes coexists at greater frequency with dyslipidemia, hypertension, central obesity, and micro-albuminuria, which markedly increase the risk and accelerates the course of atherosclerotic diseases (3).
\end{abstract}

Abstract

Diabetes mellitus coexists at a greater frequency with hypertension, obesity, central obesity, dyslipedemia and proteinuria and that markedly increases the risk of atherosclerotic disease. A study was done for a period of four months in Sidama Zone, Southern Ethiopia to compare the prevalence of atherosclerotic risk factors between diabetic and non diabetic general population. One hundred ninety nine diabetic cases were selected from two hospitals diabetic clinics and 195 non diabetics subjects were selected from urban and rural areas. The general prevalence of hypertension in the entire study population was $18.8 \%$, with $26.1 \%$ in diabetics and $10.2 \%$ in non diabetics. Multivariate logistic regression showed that hypertension, central obesity, overweight and obesity, and ethnicity had strong association with possibility of diabetes mellitus. The reason for possible racial difference to cardiovascular risk factors and population awareness to these factors should be studied. [Ethiop. J. Health Dev. 2010;24(2):145-147]

There is scarcity of studies assessing diabetes and other cardiovascular risk factors in sub Saharan Africa including Ethiopia. A study done 16 years ago on Ethiopian immigrants to Israel showed that they tend to develop diabetes mellitus when exposed to civilized living style. As civilization spreads, cardiovascular diseases become increasing health burden that require skillful and cost effective management (4). In the last two decades there has been obvious change in lifestyle of urban people with significant population growth in Ethiopia. In 2007, a study conducted at the Black Lion Specialized Hospital in Ethiopia, showed that, cardiovascular diseases are the leading causes of mortality among diabetic patients (5). So it is important to assess our population cardiovascular risk factors including diabetes.

In this study of clinical evaluation and blood glucose measurement, we will try to compare the prevalence of cardiovascular risk factors among diabetics and non diabetics in southern Ethiopia.

\section{Methods}

This is a cross-sectional comparative study conducted in Southern Ethiopia at Sidama Zone from October 2008 to February 2009. Diabetic cases were selected from Hawassa University Referral Hospital and Yirgalem Regional Hospital diabetic clinics. The non diabetics control group was selected from urban and rural Sidama Zone, South Ethiopia.

The sample size was calculated using a formula for two population proportions with assumption of obesity in diabetics and non diabetics as $50 \%$ and $35 \%$ respectively, and taking $95 \%$ confidence interval and $90 \%$ power. The calculated total sample size was 222 of diabetic and non diabetics each.

Data was collected using questionnaire. The questionnaire was divided into four parts to record socio demographic factors, specific cardiovascular risk factors, blood pressure and anthropometric data and blood glucose level. The questionnaire was pre-tested on $5 \%$ of sample size. Data was collected by nurses. Training was given ahead of time for data collectors on data collection method and ethical issues. Data was collected using standardized protocol. The blood sugar was measured by glucose oxidation test at each hospital and by digital glucometer at the community level due to logistic reason.

Participants were categorized according to relative body weight status using WHO criteria (underweight: $\mathrm{BMI}<18.5 \mathrm{~kg} / \mathrm{m}^{2}$; normal: BMI 18.5-24.9; overweight: BMI 25.0-29.9; obese $\mathrm{BMI} \geqslant 30.0$ ). Participants were considered centrally obese if waist-hip ratio (WHR) was 0.95 or over for men and 0.85 or over for women.

Obtained data were cleaned, coded, recoded and edited. The analysis was done using SPSS 15.0 statistical soft ware. Chi square test and student $\mathrm{t}$-test were used for statistical analysis. P-value below 0.05 considered as statistically significant. To measure association between variables in diabetics and non diabetics a multiple logistic regression was performed.

\footnotetext{
${ }^{1}$ Hawassa University, Medical Faculty, Hawassa, P. O. Box: 1560, Tel: +251-46-2212238, Fax: 251-46-228755, e-mail: aragid2@yahoo.comEthiopia; ${ }^{2}$ Addis Ababa University, Medical faculty, Addis Ababa, Ethiopia
} 
The research was conducted after getting ethical clearance from the College Institutional Review Board, the administrative body of the kebeles, woredas and Zonal Health Bureau. Consent form was prepared in both English and Amharic languages. Informed consent was obtained from all study participants after explaining the details about the study and its objective.

\section{Result}

Out of 444 sampled study subjects 395 participated making the response rate $88.9 \%$. Out of total 395 subjects 199 (50.4\%) were diabetics and 196 (49.6\%) were non diabetics with nearly equal representation. Among the diabetics $152(76.4 \%)$ had type 1 diabetes mellitus and $47(23.4 \%)$ had type 2 diabetes mellitus. The mean age was a $36.08 \pm 14.72$ year ranging from 12 to 80 years old. Majority were out of Hawassa, 307 (77\%); male, 265 (67.1\%); married, 236 (59.7\%); protestant, 290 (73.4\%); Sidamo by ethnicity, 255 (64.6\%), and 266 (67.3\%) had low level education. Barefoot is used for transportation in most days for 367 (92.9\%) participants.
Family history of hypertension and sudden death were found in $36(9.1 \%)$ and $21(5.3 \%)$ of subjects respectively. Mean body mass index was 21.79 $\pm 4.15 \mathrm{~kg} / \mathrm{m}^{2}$ and mean waist to hip ratio was $0.93 \pm 0.12$. Two hundred sixty $(65.8 \%)$ were centrally obese, 53 $(13.4 \%)$ were overweight and $11(2.8 \%)$ were obese.

Mean systolic blood pressure was $116.54 \pm 17.59 \mathrm{mmHg}$ and mean diastolic blood pressure was $75.57 \pm 11.10 \mathrm{mmHg}$. The prevalence of hypertension according to WHO definition (systolic blood pressure $\geq 140 \mathrm{mmHg}$ and/or diastolic blood pressure $\geq 90 \mathrm{mmHg}$ or taking antihypertensive medication) was found to be 18.8\%. According to JNC-7 criteria, 177 (44.8\%) had pre-hypertension and $73(18.8 \%)$ had hypertension.

Those variables which showed significant difference on binary logistic regression were inserted to multivariate regression model (see Table 1).

Table 1: Multivariate logistic regression analysis: predictors of diabetes mellitus when compared to non diabetic general population, Sidama Zone, Ethiopia, 2008

\begin{tabular}{|c|c|c|c|c|c|c|}
\hline \multirow{2}{*}{\multicolumn{2}{|c|}{ Variables }} & \multirow{2}{*}{$\begin{array}{l}\text { DM } \\
\text { No. }(\%)\end{array}$} & \multirow{2}{*}{$\begin{array}{l}\text { Non DM } \\
\text { No. }(\%)\end{array}$} & \multirow{2}{*}{$\begin{array}{l}\text { Crude OR } \\
(95 \% \mathrm{Cl})\end{array}$} & \multirow{2}{*}{$\begin{array}{l}\text { Adjusted OR } \\
(95 \% \mathrm{Cl})\end{array}$} & \multirow[t]{2}{*}{$P$ value } \\
\hline & & & & & & \\
\hline Hypertension & Yes & $52(72.2)$ & $20(27.8)$ & $3.113(1.778-5.451)$ & 4.87 (2.06-11.49) & $<0.001^{*}$ \\
\hline & No & $147(45.5)$ & $176(54.5)$ & & & \\
\hline Ethnicity & Sidama & $143(56.1)$ & $112(43.9)$ & $1.915(1.26-2.912)$ & $4.36(2.04-9.34)$ & $<0.001^{*}$ \\
\hline & Others & $56(40)$ & $84(60)$ & & & \\
\hline Waist to hip ratio & $\begin{array}{l}\text { Central } \\
\text { obesity }\end{array}$ & $152(58.5)$ & $108(41.5)$ & $1.889(1.189-2.995)$ & $3.96(1.76-8.92)$ & $0.001^{*}$ \\
\hline & Normal & $44(42.7)$ & $59(57.3)$ & & & \\
\hline Body mass index & $\geq 25 \mathrm{~kg} / \mathrm{m}^{2}$ & 46 (71.9) & $18(28.1)$ & $2.97(1.65-5.34)$ & $2.83(1.11-7.26)$ & $0.033^{*}$ \\
\hline & $<25 \mathrm{~kg} / \mathrm{m}^{2}$ & $153(46.2)$ & $178(53.8)$ & & & \\
\hline Family history of & Yes & $17(47.2)$ & $19(52.8)$ & 3.599 (1.729-7.491) & $1.90(0.72-5.03)$ & 0.204 \\
\hline & No & $44(19.9)$ & $177(80.1)$ & & & \\
\hline Sex & Male & $152(57.4)$ & $113(42.6)$ & $2.38(1.54-3.66)$ & $1.58(0.71-3.54)$ & 0.261 \\
\hline & Female & $47(36.2)$ & $83(63.8)$ & & & \\
\hline $\begin{array}{l}\text { Family history of } \\
\text { Sudden death }\end{array}$ & Yes & $11(52.4)$ & $10(47.6)$ & $\begin{array}{l}4.092 \\
10.181)\end{array}$ & $1.03(0.27-3.89)$ & 0.966 \\
\hline & No & $50(21.2)$ & $434(78.8)$ & & & \\
\hline
\end{tabular}

'DM' means Diabetes Mellitus; 'Fhx' means family history

* $=\mathrm{P}$ value below 0.05 considered statistically significant

\section{Discussion}

In this study, the majority of the participants were young with mean age of 36 years and only $9.1 \%$ were above the age of sixty, and this age profile is near to mean age of the study done in Iran (6).

Even though the selection was random most of the volunteer participants were male, who were disproportionately represented by diabetes. However, in most studies women were either equally or highly affected by diabetes (7). The reason for highly represented diabetes by males in this study could be due to the living status of male population in the region, who could have access for high calorie diet and sedentary work environment or it could be due to high health seeking behavior and access of health service.

Type 1 diabetes mellitus constituted $76.4 \%$ of diabetics, which may not be representative of the general population. This could be due to younger volunteer participants or type 1 diabetic patient's public institutions preference to get low cost insulin. The other possibility is mislabelling of type of diabetes.

Among all participants, $18.8 \%$ were hypertensive, which was $23.1 \%$ among diabetics and $10.2 \%$ in non diabetics with statistically significant difference between the two groups. The association of hypertension and diabetes 
mellitus were seen in many studies particularly with type 2 diabetes mellitus (8- 10).

Central obesity and obesity were highly associated with diabetic participants. Central obesity was found significantly higher in female than male irrespective of having diabetes mellitus, but obesity had no significant difference among both sexes. Abdominal obesity had a graded relationship with diabetes mellitus in both male and females (9). In many studies not only central obesity, but also obesity and higher body mass index were observed among females (10).

Sidama ethnicity had significant association with diabetes. This difference could be due to the largely represented Sidama population or due to different lifestyles which predispose for diabetes. Ethnic and racial differences with prevalence of diabetes were seen in some studies (11).

Studies done on Ethiopian general population to determine cardiovascular risk factors found that hypertension is common particularly in urban areas like Addis Ababa the prevalence being as high as $31.5 \%$ in males and $28.9 \%$ among females (12). The associated risk factors for cardiovascular disease are drinking alcohol, smoking cigarette and 'khat' chewing.

In conclusion, Hypertension, central obesity, overweight, obesity and ethnicity were found to be significantly associated with risk of having diabetes. The possible association of being male single and married, having family history of hypertension and family history of sudden death with diabetes were also observed. The comparison of prevalence of hypertension, obesity and central obesity in diabetics and non diabetics in this study was similar to many studies.

As per the study findings, we recommend that further study should be done to identify reasons for possible racial difference and population awareness for various cardiovascular risk factors.

\section{Acknowledgements}

We like to thank NPT 107 Ethiopia for their financial support. We like to forward special gratitude for Dr. Mark Spigt and Dr. Geent Jan Dinant for their valuable comments on the proposal.

\section{References}

1. Campbell RK. Type 2 diabetes: where we are today: an overview of disease burden, current treatments, and treatment strategies. J Am Pharm Assoc (2003). 2009 Sep-Oct; 49 Suppl 1:S3-9.
2. Levitt NS. Diabetes in Africa: epidemiology, management and healthcare challenges. Heart. 2008 Nov; 94(11):1376-82.

3. Yusuf S, Hawken S, Ônpuu S, Dans T, Avezum A, Lanas F, et al. Effect of potentially modifiable risk factors associated with myocardial infarction in 52 countries (the INTERHEART study): case - control study. Lancet 2004; 364(9438):937-52.

4. Motlagh B, O'Donnell M, Yusuf S. Prevalence of cardiovascular risk factors in the Middle East: a systematic review. Eur J Cardiovasc Prev Rehabil. 2009 Jun;16(3):268-80.

5. Feleke Y, Mengistu Y, Enquselassie F. Diabetic infections:clinical and bacteriological study at Tikur Anbessa Specialized university hospital, Addis Ababa, Ethiopia. Ethiop. Med J 2007 Apr 45(2):171-179.

6. Zhou L, Deng W, Fang P, He D, Zhang W, Liu K, et al. Prevalence, incidence and risk factors of chronic heart failure in the type 2 diabetic population: systematic review. Curr Diabetes Rev. 2009 Aug; 5(3):171-84.

7. Flu HC, Tamsma JT, Lindeman JH, Hamming JF, Lardenoye JH. A Systematic Review of Implementation of Established Recommended Secondary Prevention Measures in Patients with PAOD. Eur J Vasc Endovasc Surg. 2009 Nov 10.

8. Nemesure B, Wu SY, Hennis A, Leske MC. The relationship of body mass index and waist-hip ratio on the 9-year incidence of diabetes and hypertension in a predominantly African origin population. Ann Epidemiol 2008; 18(8):657-63.

9. Mengesha B, Abdulkadir J. Heritability of diabetes mellitus in Ethiopian diabetics. East Afr Med J 1997 Jan; 74(1):37-40.

10. Zung A, Elizur M, Weintrob N, Bistritzer T, Hanukoglu A, Zadik Z, et al. Type 1 diabetes in Jewish Ethiopian immigrants in Israel: HLA class II immune-genetics and contribution of new environment. Hum Immunol 2004; 65(12):1463-8.

11. Maty SC, James SA, Kaplan GA. Life-Course Socioeconomic Position and Incidence of Diabetes Mellitus among Blacks and Whites: The Alameda County Study, 1965-1999. Am J Public Health 2009 Feb 5.

12. Tesfaye F, Byass P, Wall S, Berhane Y, Bonita R. Association of smoking and khat (Catha edulis Forsk) use with high blood pressure among adults in Addis Ababa, Ethiopia, 2006. Prev Chronic Dis 2008 Jul;5(3):A89. 